\title{
A Study for Improving Youth Voter Participation
}

\author{
Claire Zhu \\ California, April 2021
}

\begin{abstract}
Youth voters between 18 and 29 years of age have consistently had the lowest turnout among all age groups in U.S. presidential elections. While this is well known and studied, there does not appear to be a fundamentally effective solution for this situation. More research is warranted to further understand what it would take to motivate young voters to take civic action.

Based on the outcomes of my previous researches studying youth turnout impact on presidential election results and major factors influencing voter participation, this paper examined voting behavior of young adults, using a youth's viewpoint, and documented the results of the study - a framework for improving youth voting rate, which consists of:

- engagement strategies focusing specifically on youth and starting to work with them from before the voting age, and

- actionable steps, grouped into five areas, i.e. early engagement, education, community influence, social media, and technology.
\end{abstract}

\section{KEYWORDS}

Youth voter turnout; Elections; Voting behavior; Voting rate; Social media; Community influence

\section{INTRODUCTION}

\section{A. Background and Objective}

As the 2020 election is now behind us, a new 4-year presidential election cycle starts. There are many factors that will sway the voters and affect the next election's results: politics, economy, society, technology, healthcare, and others. These factors have played important roles in candidates' and political parties' campaign strategies in modern era elections.

In the end, however, it all comes down to the voters.

With the Census Bureau data of the presidential elections from 1980 to $2016^{[\mathrm{I}-1]}$, Diagram I-A-1 illustrates that younger Americans, i.e. 18- to 29-year olds, always had much lower voting rates when 
compared to older age groups. Although, according to estimates ${ }^{[-2]}$ by the Center for Information and Research on Civic Learning \& Engagement (CIRCLE), youth voter turnout in the 2020 election was about $10 \%$ higher than that of the 2016 presidential election, this age group was still the least participating and hence a much less influential population on the nation's political stage.

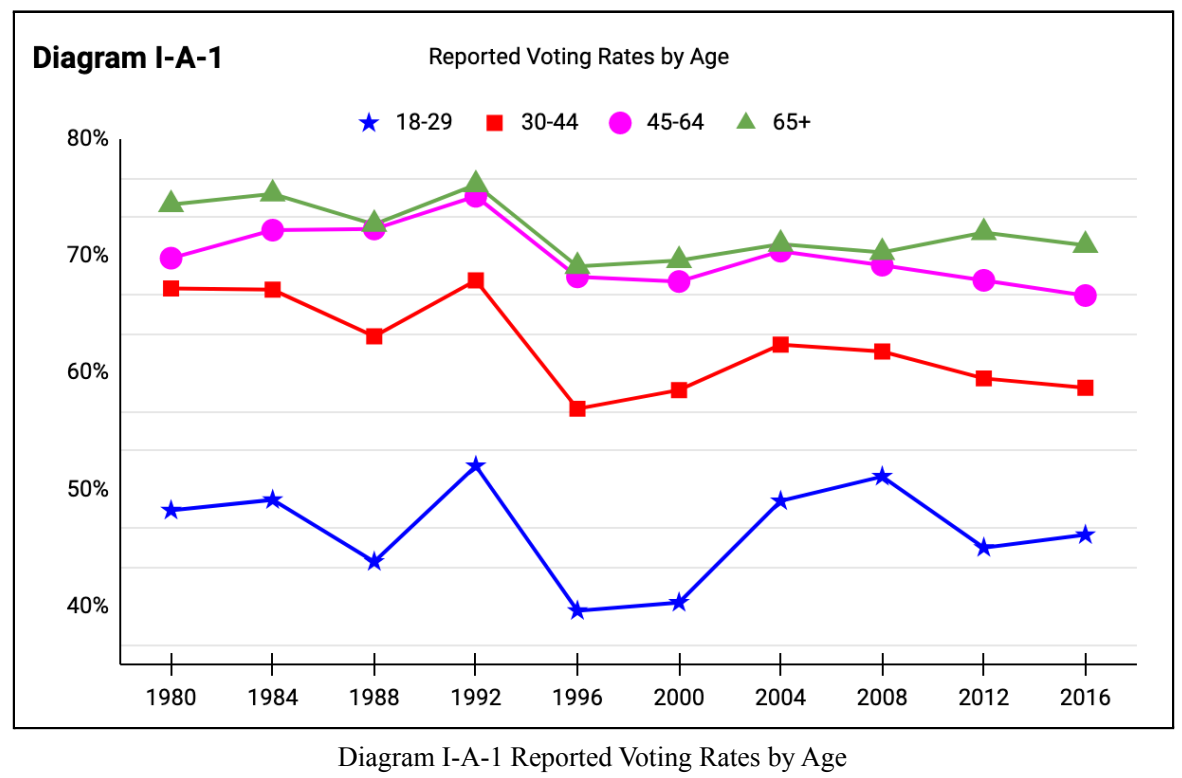

Common beliefs attribute the situation to inadequate civic education, complex registration and voting, and political apathy, among others. Scholars have also discussed various theories about the cause of the stubbornly low youth turnout, including, for examples:

- Young people are habitual nonvoters and develop into habitual voters, according to Professor Eric Plutzer's article, "Becoming a Habitual Voter: Inertia, Resources, and Growth in Young Adulthood"[-3].

- While not lacking interest in politics and motivations, young voters need the skills related to self-regulation to overcome internal and external barriers to vote, detailed in the book "Making Young Voters: Converting Civic Attitudes into Civic Action" by Professor John Holbein and Professor D. Sunshine Hillygus ${ }^{[--4]}$.

- The mutual neglect between politicians and young adults widens "the age bias in electoral participation", and changes in media habits have led to the situation in which young people are far 
less likely to be exposed to news about public affairs, stated in the book, "Is Voting for Young People”, by Professor Martin P. Wattenberg ${ }^{[--5]}$.

In recent decades, the 18 - to 29 -year-old age group has had 50 million or so eligible voters. While that accounts for about $20 \%$ of all legal voters, several factors need to be considered when trying to understand the role of young people in presidential elections:

- Are the number of votes from this group enough to make a significant impact on election results if they choose to participate more actively, and,

- If so, how do we better work with these young people, starting before they become eligible to vote, in order to improve their turnout?

This research was designed to study and answer the second question in particular. The objective was to establish a framework, entirely coming from a youth perspective, for meaningfully engaging the young people starting from their pre-voting-eligible ages and encouraging them to vote. (A separate paper, "A Data-Driven Analysis of Youth Turnout Impact on U.S. Presidential Elections", detailed the research focused on the first question above.)

\section{B. Methodology and Approach}

This research studied how to most effectively develop youth interest and ability in taking part in the democratic process and the intricacies involved in doing so, with the following approaches:

- Emphasizing using a youth perspective to look at all issue, situations, and resolutions throughout the process

- Starting with major factors that are known to impact voter turnout to determine their distinct influence, or lack thereof, on young voters (the study of the factors is detailed in the paper, "A Study of Key Factors Influencing Youth Voter Turnout")

- Developing an engagement framework by considering psychological, social, and technological aspects that are unique to this age group and would encourage youth voter participation

- Not stopping at theoretical analysis, but also identifying courses of actions for practical purposes, 
with actionable steps specifically addressing the generally accepted causes of low turnout as well as those causes identified by the academics

With that, the results of the research presented unique academic and practical values.

\section{Value and Use}

Youth before and even after becoming eligible to vote are at a stage in their lives when they are figuring out their political identities and stances. The engagement framework developed by this research provides guidance specific to working with this group. Using the resulting strategies and actionable steps, candidates, political parties, and civic groups can make an informed decision on how to most optimally engage youth in order to achieve their goals in elections.

\section{YOUTH ENGAGEMENT FRAMEWORK}

\section{A. Strategies}

Before developing an effective working approach to prepare and energize the future and current young voters for their impactful turnout, it is important to first devise proper strategies that are much different from those targeting the general voting age population. Any political parties, organizations, or civil groups looking to win young voters' support of their causes need to understand:

- The 50 million 18- to 29-year-old voters are of strategic importance to any election. Only when this is properly recognized, the deserving attention will then be given to this age group, along with adequately allocated resources and devoted efforts.

- It is essential to start working with the youth even before they become eligible voters, so they are well prepared and ready to engage in the political processes. Instilling a sense of importance and responsibility about the civic duty and democratic principle from an early age would encourage more and consistent participation in elections in their future years. This kind of outreach to future voters, with patience, consistency, and a long-term view, will improve the election turnout of the young people in due time. 
- Youth respond to voter engagement efforts significantly differently from older age groups. Past working methods cannot simply be applied to the future and current young voters and expect to be effective as well. It is critical to design and implement thoughtful courses of actions that are tuned to the young generation, given their unique social environment, life experience, psychological state, and other age-specific characteristics.

\section{B. Actions}

A well-coordinated and comprehensive action plan for working with the next generation will fundamentally boost their engagement. Under the guidance of the strategies discussed above, action items were defined, grouped into five areas, and detailed below. It is evident that the actions will require grass-root efforts, legislature-level support, or both, to be successful.

\section{Encourage and enable proper early participation.}

It is essential to establish positive experiences about election early on in one's life, so once at voting age, young people will participate with the right mindset. Local officials, candidates, educators, community leaders, and family members can start with the following:

Reach out to pre-voting age youth as if they were voters. Youth will feel more respected and encouraged to voice their opinions, as well as grow their knowledge of civic processes. Political groups will be able to convey their stances on issues and other matters so youth will be able to make well-informed decisions when they can vote. Additionally, this action is important as it does not only encourage youth to participate in the future, but it also gives them the confidence to be sure of their political decisions and actions, the lack of which has been a major cause of lowered participation. For example, Home Depot has long held workshops for children aimed to educate and boost their interest in building, renovating and repairing, which will foster interest and longtime engagement with the brand. Similarly, keeping voters-to-be involved with the political environment early on, e.g. setting up a youth forum where a campaign is going on for the voters, would likely promote a lifetime of active electoral participation. 
Involve youth with causes they care about first. Many political topics that may not have much to do with younger voters can be alienating. However, youth have been historically and presently known to be very involved or at least interested in social causes. For example, in 2020, the Black Lives Matter movement became very prominent, with even minors who could not participate in protests taking part on social media, supporting black creators, and helping to spread the message. This shows how, when youth, especially ones belonging to underrepresented minorities, feel connected to a cause, they are more than willing to take action. Groups focusing on raising youth participation should be aware of and bring to light issues that affect youth more, and should give attention to their voices.

Treat student body government elections as serious matters. This is one of the first opportunities youth go through a democratic process. However, student body government at middle and high school level is often mismanaged and elections not taken seriously. A common theme among these elections is the basis of popularity as a sole factor for voting. Qualifications, stances, or ideas that would matter in actual elections outside of school are practically nonexistent in these settings. As a result, many students who are considered voters become bored of the elections, not bothering to listen to candidates' speeches or even participate in voting, which sometimes happens through an unceremonious online optional survey, likely disillusioning them with elections outside of school in their future. Furthermore, the student body government becomes just a label, as very little action or change is actually made.

While it is a good idea to introduce the concept of democracy in a safe school environment, if it is not done right, the young students will have less trust in the process when they enter adulthood and less likely turn out to vote.

Start youth smaller with local elections. Encouraging young people for larger elections should start with getting them motivated to be part of smaller, more local ones. This would allow them to be more directly involved with issues in their own communities, and see how the democratic process produces results on the issues that are nearer and more personal to them. Taking part in voting or supporting the campaign for mayor, school board of trustees, district representatives, or even the school district bond 
measures would give youth more knowledge and faith in the process of elections and taking responsibility for their rights.

Incentivize initial participation to nurture long-term activeness. Another seemingly simple way to encourage young people to participate in the voting process would be to have some sort of "reward" system. As youth would probably be more concentrating on school and studies than elections, which seem further away from them, high school teachers, for example, could offer extra credit to students who vote. This would apply only to high school seniors who are eligible to vote, with a few exceptions. But involving a sizable group of students would likely generate more interest in underclassmen as well. The extra credit would potentially encourage many students to vote, "killing two birds with one stone" by helping in both academics and civic participation. Of course, teachers need to be careful not to direct students' choices when giving incentive to vote.

Make it safe for youth to talk about politics. Most teens nowadays don't typically talk much about subjects related to government or politics, especially in public settings like school. There has always been controversy about politics among students and teachers, especially in the current divided political landscape of this country, and people don't feel comfortable sharing their opinions, which can be very polarizing. Although cautioning against politics in the classroom is reasonable, it's essential to establish a safe space where students and teachers can treat each others' opinions with respect. It would also be beneficial to analyze biases and beliefs without judgement on the students themselves. Not only would young people have a better understanding of politics around peers, but they would also become more prepared to discuss outside of school. Furthermore, by talking about the issues the society has is the first step for the youth to become aware of the problems, then they would have the opportunity to understand the political and democratic process to seek the right leaders and implement the right policies to solve them.

If youth were more open and willing to discuss politics without fear of being ostracized or judged, they would be able to participate more. It is up to the school administration, local leaders, political parties, and 
civic groups to create such a safe environment or forum, so the young people don't distance themselves from these tough topics and become active participants when they are ready to vote.

\section{Start with education.}

Many aspects of education have a big role in preparing the young generation for their civic duties. Actions from lawmakers at all levels, civic groups, local leaders, school and district administration, educators, and curriculum developers will be able to make a meaningful and positive change in this respect.

Recognize the importance of civic education. The education system in the past couple of decades or so has prioritized areas such as STEM and literature over civics. For example, the No Child Left Behind Act of 2001 placed a stronger emphasis on language arts and mathematics and less on social studies and civic education.

According to the article "Most \& Least Politically Engaged States" ${ }^{\text {[II-2] }, ~ “ . . . m o s t ~ s t a t e s ~ d o n ’ t ~ e m p h a s i z e ~}$ civic education in their schools. Large proportions of the public fail even simple knowledge tests such as knowing whether one's state requires identification in order to vote." With civic education clearly seen as less of a priority for students, it unavoidably has adverse impacts on the political involvement of young Americans. In addition, the passing requirements of social study courses in high school are less strict than those of other courses. Less stress placed on these subjects adds to a lack of knowledge of high schoolers, such as the function of the Electoral College or party differences.

Apart from the substances of politics, students are rarely ever taught about the procedural aspect of politics, e.g. how to vote. For major elections, the registration processes can be very complicated, deterring many to complete or even look into the steps. As for more local or state elections, voting is barely touched upon or mentioned to students.

Those are the reasons why teenagers feel like they are not educated enough to vote, hence a very low turnout. It does not take one to look far to find a fix of this issue in the education system. Like sex education and mental health are covered in occasional seminars in most high schools, voting processes 
and information should also be given straightforwardly. Students would benefit from learning about polling places in their local areas, how to complete a ballot, and so on. Another way would be to have a dedicated class with a focused curriculum on elections, politics, and important, often-argued topics in the political landscape, similar to Home Economics or Life Skills classes, as they are all important parts of an adult life.

All leaders in the education systems should work to emphasize and correct the course of civic education in this country so students are given an opportunity to learn.

Destigmatize politics in school. While teachers in public schools are currently not allowed to talk about politics, they should be encouraged to, in an unbiased and factual manner and on a formal platform. When teachers aren't permitted to share their views on political matters, a certain stigma concerning politics is perpetuated. Trying to keep political opinions from the classroom by completely banning any talk about politics is not going to help the students, or in the long run, the country at all.

One observed example of an unbiased and educational assignment by a middle school history teacher was requesting students to watch the State of the Union address. Students were instructed to take notes using a graphic organizer with different important topics. In the following class, these topics were discussed and explained in detail, without the teacher expressing biased opinions. This way, students gained higher understanding of and were more involved with the workings of our country. Peers also became more comfortable openly discussing such topics with each other. The destigmatization of politics provided the students more useful and topical insight into both present events and history.

Give more importance to education overall. Education is a factor impacting voter turnout, and data shows that:

- There is a clear positive correlation between higher levels of education and higher voting rates ${ }^{[\mathrm{II}-3]}$.

- States with the top ranking of the percentage of people with a higher education degree have also been rated as more politically engaged ${ }^{[\mathrm{II}-2]}$.

This calls for a significant improvement of education in the country, so more students are prepared for 
college study and see it as a viable path coming out of high school.

For the current youth, aside from lack of history and civics knowledge, there's also a considerable amount of ignorance about other topics relating to science and literature, when compared to students in other developed nations. Because weighing political issues and policy proposals need a wide range of knowledge, this is problematic as youth could be turning out to vote without proper understanding of issues on ballots or about candidates, or could be intimidated enough not to vote at all.

This lack of a quality education system could be related to the lack of importance the American government and society place on education in general. Teachers have been known to receive less pay than other professions. Because of this, recruiting highly qualified educators has become difficult due to competition with other job markets. In addition, low pay can also affect teachers' motivation, which would in turn affect performance in classrooms. According to an Allie Bidwell's article on the U.S. News ${ }^{[I-4]}$, The State of America's School Report by Gallup showed that nearly $70 \%$ of surveyed teachers were "not emotionally connected to or are dissatisfied with their workplaces". Teachers' low engagement and passion in their jobs are troublesome and can be evident to students. Findings from research documented in the book "How Does Teacher Pay Compare? Methodological Challenges and Answers"[II-5] confirm that "...teacher quality is key to student and school success" and a "continuing issue is whether teacher pay is sufficient to attract and retain quality teachers: trends in relative teacher pay seem to coincide with trends in teacher quality over the long run." So, in order to improve education and in turn produce adequately educated students to cast well-informed votes, more attention needs to be given to teachers' pay as a first step.

The other issue plaguing the country's education system is the inaccessibility of higher education and enormous student debt. Many people cannot go to college because they are unable to afford it, leading to unfavorable social consequences, with low young voter turnout being one of them. Addressing the issues of student debt and unchecked rising of tuitions is imperative for many reasons, including the need of improving youth voting rates. 


\section{Utilize social media.}

Social media has played major roles in political activities in the past decade. As it is so pervasive among youth, social media should be recognized as a major tool in engaging the younger generation in politics by the campaigns, political groups, and advocates.

Using social media as a positive channel. During the Black Lives Matter movement, many people, including youth, supported the cause on multiple social media platforms, such as by making art or informative posts on Instagram educating people about the movement. These posts with positive messages were highly influential and particularly effective in reaching teens.

If candidates want to get more people engaged, especially soon-to-be and young voters, social media ads and communications should have more relevant subject matters, addressing actual topics and stances, over only touting their own character without supporting proof. At the same time, running negative campaigns targeting opponents' characters are often turned into "memes" or funny posts on social media, debasing the seriousness of the election in teenagers' minds and taking the focus away from the voting issues at hand.

Using social media smartly. The wrong usage of media and social media can work against the purpose of increasing voter turnout. Here are several key ones identified through this research:

- Repeated political ads on media platforms from candidates are largely insipid and boring to watch. Repetition soon becomes redundancy, which turns teenagers and likely other viewers off from being interested. Instead of bombarding the viewers with the same content over and over again, more effective social media tactics would be running a multitude of different ads that address specific, different topics. More fresh and diverse information will be more effective in intriguing and engaging younger audiences.

- Although generalities can be used in online campaigns to increase emotional response, they get extremely tired and overused. To teenagers, they can easily feel dishonest, unoriginal, unresearched, and obnoxious. So, even though an exciting and exaggerated subject line can be used to pique 
interest initially, candidates should follow up with actual, factual, and substantive information to assure audiences of their credibility. What many youth want is to be validated and respected as coming adults, and ads of generality or oversimplification do not help with that.

- Sometimes, online polling requires giving personal information. Because young people are often warned against divulging such details, this is not a prudent way to connect with this age group.

Given its ability to reach so many people, social media should be used as an effective tool to spread the message about the necessity of youth participation and voting. The message should be developed in a way unique to the young generation of this time that will resonate the most, and delivered in a fashion that will catch their attention. For example, ahead of the 2020 presidential election, Facebook gave reminders for voter registration on its app, which was simple, clear, and unobtrusive.

\section{Take advantage of community influence.}

Someone growing up in an environment unwilling to talk about politics, or not strongly involved in it, is more likely to act the same way. A person's immediate community, e.g. family, friends, and peers, usually influences their ideas on politics to a fairly significant degree. According to an article by BBC political reporter Gavin Stamp ${ }^{[\mathrm{II}-6]}$, an Opinion Matters survey of more than 2,500 showed that "one in four adults still base their decisions primarily on discussions with either family or friends... For 18- to 24-year olds, the figure is even higher. One in three claim family or peer group influence as the decisive factor when casting their vote, compared with only $5 \%$ likely to be swayed by a face-to-face visit from a canvasser." There are several ways to take advantage of the power of community influence, as discussed below.

Surround future voters with positive influences. When trusted adults in one's family, circle of friends, school, and workplace are active participants in elections, they become a positive influence for forming voting habits. Like any habit, it is easier to start at an early age. Children who have been taken to polling stations with their parents, heard discussions about politics at family gatherings, or seen community members attending campaign rallies are more likely to take on those same behaviors. These types of 
immersive influences from community members are much more relevant and personal in engaging the young voters than most traditional campaigns or canvassers can deliver.

Nowadays, many teenagers and young adults think that what they know might not make them qualified or smart enough to make a rational vote, and their votes won't count for anything or make a difference. To break this sort of learned helplessness, they need to receive support and encouragement from peers and trusted members in their families, neighbourhoods, and communities. Successfully tweaking this mentality would inspire them in multiple ways; they would feel more motivated to openly learn about different aspects of politics, take the initiative to discuss with others, and eventually register and cast their votes by overcoming various hindrances. At a time of great change in growing up, it's essential for the community to help youth understand their importance and that they can and should make impacts on their society.

Enable adults to work with young people. In order to encourage more youth to vote, it's important for their families and immediate circle of life to be open and active about politics and voting. It is also important that they know how to properly converse with the next generation who often have quite different opinions. Political parties, nonpartisan or bypartisan organizations, and civic groups should develop, provide, and distribute tips, tools, and approaches on how to talk about politics from parent to child and from trusted adults to youth, despite possibly conflicting views. Educational pamphlets can be placed in DMV offices, postal offices, and public libraries. Pediatricians' offices are also ideal locations for distributing such materials. Just as the pamphlets already there related to youth mental health, making friends and finding hobbies, those information about properly talking about the country's political processes are equally important to the youth's healthy upbringing and future well-being.

\section{Use technology appropriately.}

Technology is an integral part of our daily lives, and in recent years, a much controversial focal point on the political stage of this country. It is more and more inseparable from the elections and campaigns, and requires that the legislative body, regulators, advocacy groups, and technology companies work 
together to make things right.

Stop misinformation. Technology has enabled the broad distribution of information from the original sources with one click. Social media, mass emailing, and online ads are all powerful tools to reach an audience of millions with ease. Along with facts and truth, misinformation can spread like wildfire, which is especially misleading to youth. Companies like Facebook and Twitter have started to moderate posts and label false information on their platforms in recent years and close down accounts when necessary. Because of these activities, the following issues require immediate attentions and solutions:

- Are private companies to be entrusted with the responsibilities to make the unbiased judgement call of true versus false information?

- How can freedom of speech be ensured and uninfringed while malevolent attempts of spreading misinformation is stopped?

Fact-checking performed by trustworthy organizations should become a more utilized practice to prevent people from being exposed to misinformation. In addition, various social and traditional media sites need to always be conscientious about the information spread on their platforms, with proper oversight and guidance from regulators and independent groups to hold them accountable.

Stop the echo-chamber effect. The unprecedented level of divisiveness the country is experiencing in the recent years is the results of political polarization. Among many causal factors, the echo-chamber effect enabled by online targeting technology is also to blame.

For the purpose of digital marketing, this technology was initially developed to deliver online ads and contents accurately to consumers based on their demographics and past behaviors. As it has been refined in the last two decades by the leading social media companies, online targeting technology has since been used for curating political natured campaigns, news feeds, and user created contents, with the purpose of retaining the users on their platforms by delivering information that they are comfortable to consume. Potential voters are repeatedly fed with similar information in alignment with their previously held beliefs, de facto narrowing their perspectives and limiting their ability to see the opposing views or the 
whole picture. Gradually, these voters harden up their one-sided opinions and become ardent supporters of others who hold firm the same type of views.

When young and future voters are targeted with technology in the same manner, they are deprived of the opportunity to make their own judgement calls based on the complete information they should be given. Growing up in such a bubble-like environment, the young voters will not become healthy participants of the political activities, nor will they turn into informed, thoughtful, and knowledgeable voters.

It is imperative that the leading technology companies and multidisciplinary scientists recognize and accept this issue as the first step. With undeniable social responsibilities, they need to work together to solve the problem for the well-being of the future generation and the country overall.

Build civic technology that comes with accessibility, integrity and modernization. Technology has always been an enabler in human evolution history. In the 21 st century, it has an inherent role in the political process. Civic technology has come a long way already. For example, the Dominion and Smartmatic voting machines, which have held up to the tasks of many close contests, provide election support services with technology. Voters in many states and counties are now able to track the lifecycle of their ballots from being cast to being counted on their mobile phones. Governments are increasingly providing more services online as well.

There is much more can be done with the technology to motivate and engage future and young voters:

- A solution that connects upcoming voters to the politicians and governments, much like a youth version of POPVOX that is suitable to the manner of how young people seek, consume and respond to information.

- A platform that is not profit driven, but performs like social media, that distributes factual and truthful political information and invites constructive conversations.

- A modern method, much streamlined, intuitive, and convenient, that encourages young voter registration when they come of age, and then possibly a solution for online voting that is much 
more accessible and secure than the traditional in-person and absentee voting processes.

With necessary oversight, independent groups and organizations, private companies and industries, and teams within government all need to build the right civic technology for the next generation political apparatus and voters.

\section{CONCLUSION}

The research continues to put the young voter engagement strategies and action items into practice, by identifying and then working with government organizations, political parties, and civic groups, in order to deliver the research's ultimate goal: fundamentally improve young voter turnout in the elections as an impactful force in the country's democratic process. 


\section{ACKNOWLEDGEMENTS}

I am most grateful to political scientist Robert Y. Shapiro, a professor and former chair of the Department of Political Science at Columbia University, for his enthusiastic support. Professor Shapiro reviewed multiple versions of my paper, and provided invaluable feedback on not only the research project itself but also the writing of the paper. His continued encouragement and advice resulted in important improvements in the paper, a clearer path to submission for publication, and next step research directions. As a young researcher, I couldn't be more fortunate to have had Professor Shapiro's valuable time and attention on my project. 


\section{REFERENCES}

[I-1] File, Thom. "Voting in America: A Look at the 2016 Presidential Election". United States Census Bureau. 10 March 2017. https://www.census.gov/newsroom/blogs/random-samplings/2017/05/voting_in_america.html

[I-2] "Youth Voter Turnout Increased in 2020". CIRCLE. Updated 18 November 2020. https:/circle.tufts.edu/index.php/latest-research/election-week-2020\#youth-voter-turnout-increasedin-2020

[I-3] Plutzer, Eric. "Becoming a Habitual Voter: Inertia, Resources, and Growth in Young Adulthood". The American Political Science Review, Volume 96, No. 1, Pages 41-56. March 2002. https://www.jstor.org/stable/3117809

[I-4] Holbein, John B., Hillygus, D. Sunshine. "Making Young Voters: Converting Civic Attitudes into Civic Action". Cambridge University Press. February 2020. https://doi.org/10.1017/9781108770446

[I-5] Wattenberg, Martin P. "Is Voting for Young People?" (5th Edition). Routledge. 27 April 2020. https://www.routledge.com/Is-Voting-for-Young-People/Wattenberg/p/book/9780367445522

[II-1] Edelson, Sharon. "Home Depot Makes A Loyalty Play With New Kids Program". Forbes. 22 October 2020.

https://www.forbes.com/sites/sharonedelson/2020/10/22/home-depot-hopes-new-kids-program-insp ires-tykes-to-become-junior-mr-and-ms-fix-its/?sh=12cb97bb2b06

[II-2] McCann, Adam. "Most \& Least Politically Engaged States.” WalletHub. 13 October 2020. https://wallethub.com/edu/most-least-politically-engaged-states/7782

[II-3] "Table A-2. Reported Voting and Registration by Region, Educational Attainment and Labor Force Status for the Population 18 and Over: November 1964 to 2018." US Census Bureau. https://www2.census.gov/programs-surveys/cps/tables/time-series/voting-historical-time-series/a2.x lsx

[II-4] Bidwell, Allie. "Most Teachers Are Not Engaged in Their Jobs, Gallup Finds". U.S. News. 9 April 2014.

https://www.usnews.com/news/articles/2014/04/09/most-teachers-are-not-engaged-in-their-jobs-gal lup-finds

[II-5] Allegretto, Sylvia A., Corcoran, Sean P., Mishel, Lawrence. "How Does Teacher Pay Compare? Methodological Challenges and Answers". Economic Policy Institute. 1 August 2004. https://www.epi.org/publication/books_teacher_pay/

[II-6] Stamp, Gavin. "Election: How do friends and family influence votes?” BBC News. 1 May 2020. http://news.bbc.co.uk/2/hi/uk_news/politics/election_2010/8622748.stm 


\section{Supplementary Information}

Here is additional information not shown in the main paper: the quantitative analysis of youth voter impact in Section I and the study of key factors impacting youth turnout in Section II.

\section{THE QUANTITATIVE ANALYSIS OF YOUTH VOTER IMPACT}

Please contact the research and author of this paper for a copy of the research paper, "A Data-Driven Analysis of Youth Turnout Impact on U.S. Presidential Elections".

\section{THE STUDY OF KEY FACTORS IMPACTING YOUTH TURNOUT}

Please contact the research and author of this paper for a copy of the research paper, "A Study of Key Factors Influencing Youth Voter Turnout". 